\title{
THORACIC HERNIATION OF THE TRANSVERSE COLON AFTER TRANSHIATAL ESOPHAGECTOMY
}

\author{
Juan A. Cordero, Jr, MD, and Darroch W. O. Moores, MD, New York, NY
}

Transhiatal esophagectomy has become the preferred operation of many thoracic surgeons for both benign and malignant esophageal disease. Advocates of the procedure ${ }^{1}$ cite decreased postoperative pulmonary morbidity, avoidance of an intrathoracic anastomosis, decreased suture line recurrence, and little, if any, postoperative gastroesophageal reflux as advantages. In addition, survival after transhiatal esophagectomy appears to be similar to that achieved after transthoracic resection with formal en bloc mediastinal lymphadenectomy. ${ }^{2}$ Complications of the procedure include anastomotic leak, hemorrhage, injury to the recurrent laryngeal nerve, and injury to the trachea. Herniation of the transverse colon into the chest after transhiatal esophagectomy has not previously been reported.

Clinical summary. A 62-year-old woman had a 2-month history of progressive dysphagia and a 15-pound weight loss. Examination with an esophagoscope revealed a lesion of the distal esophagus. Biopsy results of the lesion were consistent with squamous cell carcinoma. Computed tomographic scan of the chest and abdomen did not reveal any evidence of metastatic disease. A transhiatal esophagectomy and pyloromyotomy were performed. The initial postoperative course was complicated by atelectasis and bilateral pulmonary consolidations. The patient became acutely dyspneic on postoperative day 6 . A chest x-ray film (Fig 1) revealed colonic herniation into the left thoracic cavity. The patient's chest was explored via the previous midline incision and found to have a herniation of the transverse colon into the left side of the chest via the esophageal hiatus. The herniation was reduced and the diaphragmatic defect was closed. The stomach was then sutured to the hiatus anteriorly to prevent a recurrence. The patient did well postoperatively and was discharged to her home.

Discussion. Transhiatal esophagectomy without thoracotomy has gained popularity in the past 2 decades because of its potential to decrease the morbidity and mortality associated

From the Division of Cardiothoracic Surgery, Albany Medical College, Department of Thoracic Surgery, St Peter's Hospital, Albany, NY.

Received for publication Feb 24, 2000; accepted for publication March 6, 2000

Address for reprints: Juan A. Cordero, Jr, MD, Department of Surgery/A-61, Albany Medical College, 47 New Scotland Ave, Albany, NY 12208.

J Thorac Cardiovasc Surg 2000;120:416

Copyright () 2000 by The American Association for Thoracic Surgery

$0022-5223 / 2000 \$ 12.00+0 \quad \mathbf{1 2 / 5 4 / 1 0 7 2 0 7}$

doi: $10.1067 / \mathrm{mtc} .2000 .107207$

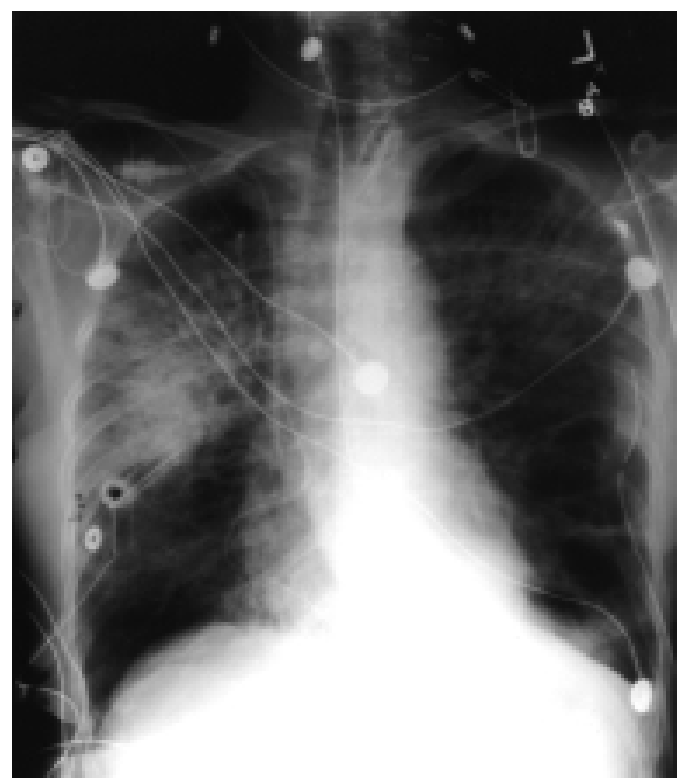

Fig 1. Chest roentgenogram demonstrates herniation of the colon into the left side of the chest.

with standard esophageal resections. Orringer ${ }^{3}$ has reported on more than 1000 transhiatal esophagectomies performed for both benign and malignant disease. Survivals after this procedure seem to parallel those of esophagectomy with formal mediastinal lymphadenectomy. Complications of the procedure include mediastinal hemorrhage, anastomotic leak, recurrent laryngeal nerve injury, and tracheal injury. Herniation of the transverse colon into the thoracic cavity has not been reported to date. As a result of our experience with this patient, we recommend suturing the stomach anteriorly to the hiatus to prevent herniation through this potential space. Since adopting this technique, we have had no further similar complications.

\section{REFERENCES}

1. Orringer MB, Marshall B, Stirling MC. Transhiatal esophagectomy for benign and malignant disease. J Thorac Cardiovasc Surg 1993;105:265-76.

2. Orringer MB. Transhiatal esophagectomy without thoracotomy. In: Orringer MB, Zuidema GD, editors: Shackelford's surgery of the alimentary tract, 4th edition, Vol I: The esophagus. Philadelphia: WB Saunders; 1996. p. 414-45.

3. Orringer MB. Esophageal tumors. In: Cameron JL, editor. Current surgical therapy, 6th ed. St Louis: Mosby; 1998. p. 58-62. 